\title{
Ranolazine for Prevention of Atrial Fibrillation after Cardiac Surgery: A Systematic Review
}

\author{
Nirav Patel ${ }^{1}$, Jeffery Kluger ${ }^{1}$ \\ 1. Cardiology, Hartford Hospital
}

Corresponding author: Nirav Patel, nirav92@gmail.com

\begin{abstract}
Postoperative atrial fibrillation (POAF) remains a major risk after cardiac surgery and is associated with an increased risk of stroke, length of stay, mortality, and cost. Ranolazine, an anti-anginal drug, also has antiarrhythmic properties. The present study is to evaluate the effectiveness of ranolazine in preventing POAF after cardiac surgery. We searched the literature for clinical studies published up to August 2017 with a predefined inclusion and exclusion criteria. We identified four studies with a total of 754 patients of which 300 patients received ranolazine; there was a $14 \%$ decrease in POAF occurrence following cardiac surgery compared to $32 \%$ in the control group. Although ranolazine is an effective therapy in prevention of POAF, larger, multi-center, randomized trials are warranted.
\end{abstract}

Categories: Cardiology

Keywords: ranolazine, post-operative cardiac surgery, atrial fibrillation, systematic review, rhythm control.

\section{Introduction And Background}

Postoperative atrial fibrillation (POAF) is a common complication following cardiac surgery, associated with high morbidity and mortality. The development of POAF depends on the patients co-morbidities and type of surgery [1], with the highest incidence of $36 \%-65 \%$ in combined coronary artery bypass grafting (CABG) and valvular surgery [2-4] when compared to valvular (30\%-40\%) [3] or CABG only (30\%) [2].

The occurrence of POAF is more frequent in patients with advanced age, left atrial enlargement, hypertension, left ventricular hypertrophy, obesity, and diabetes, and is usually evident within two to four days post surgery [5]. POAF is associated with increased risk of stroke, congestive heart failure, respiratory failure, leading prolonged hospital stay, and increase in overall health care cost [1]. Thus, chemoprophylaxis is recommended in high-risk patients [6], and therapies including beta-blockers, amiodarone, sotalol, intravenous magnesium, and steroids have proven to be effective $[1,6]$ but they are associated with side effects without altering overall hospital stay and resource utilization [6].

Received 04/02/2018 Review began 04/18/2018 Review ended 05/01/2018 Published 05/06/2018

๑) Copyright 2018 Patel et al. This is an open access article distributed under the terms of the Creative Commons Attribution License CC-BY 3.0., which permits unrestricted use, distribution, and reproduction in any medium, provided the original author and source are credited.
Ranolazine, an anti-anginal agent, exhibits antiarrhythmic effects by inhibition of late sodium (late $\mathrm{I}_{\mathrm{Na}}$ ) and potassium rectifier $\left(\mathrm{I}_{\mathrm{Kr}}\right)$ channel [7]. It produces dose-dependent block of sodium channel predominantly in the atria with significant anti-fibrillatory effect by prevention of premature atrial contraction (APC) [7]. APC is associated with atrial fibrillation (AF), and experimental and clinical studies have shown that by suppressing the APC, the incidence of atrial fibrillation (AF) is decreased [8-12]. In order to explore this hypothesis, we systematically reviewed the literature to assess the efficacy and safety of ranolazine for the prevention of POAF following cardiac surgery.

\section{Review}

\section{Methods}

This systematic review conforms to standard guidelines and is written in accordance with the Preferred Reporting Items for Systematic Reviews (PRISMA) [13]. We performed a systematic literature search using MEDLINE, Cochrane Library (1898 to 2015), Google Scholar and ClinicalTrials.gov (1997 to 2014) by using following terms "ranolazine”, “atrial fibrillation”, “cardiac surgery”, "coronary artery bypass graft”, "valvular surgery”, and "postoperative atrial fibrillation". We reviewed all potentially relevant articles in a parallel manner by pre-defined inclusion criteria. Citations to and reference lists within the selected articles were also searched for studies that would meet inclusion criteria. All retrieved references were reviewed and evaluated the clinical outcome of interest. Pre-specified selection criteria for inclusion of studies were as follows: (1) head to-head comparisons of perioperative administration of ranolazine versus placebo or other antiarrhythmic drugs or standard therapy; and (2) study participants who underwent any cardiac surgery. Case reports, letter, experimental studies, editorials, and systematic reviews and meta-analysis were excluded. The primary endpoint was the development of POAF. Other outcomes included the incidence of adverse events and early treatment discontinuation.

\section{Results}




\section{Cureus}

A total of 131 articles were retrieved and 18 articles focused on the role of ranolazine for prevention of POAF. Exclusion of case reports, letters, experimental studies, editorials, and systematic reviews or metaanalyses and screening of titles and abstracts of these references for inclusion terms resulted in four studies (Figure 1).

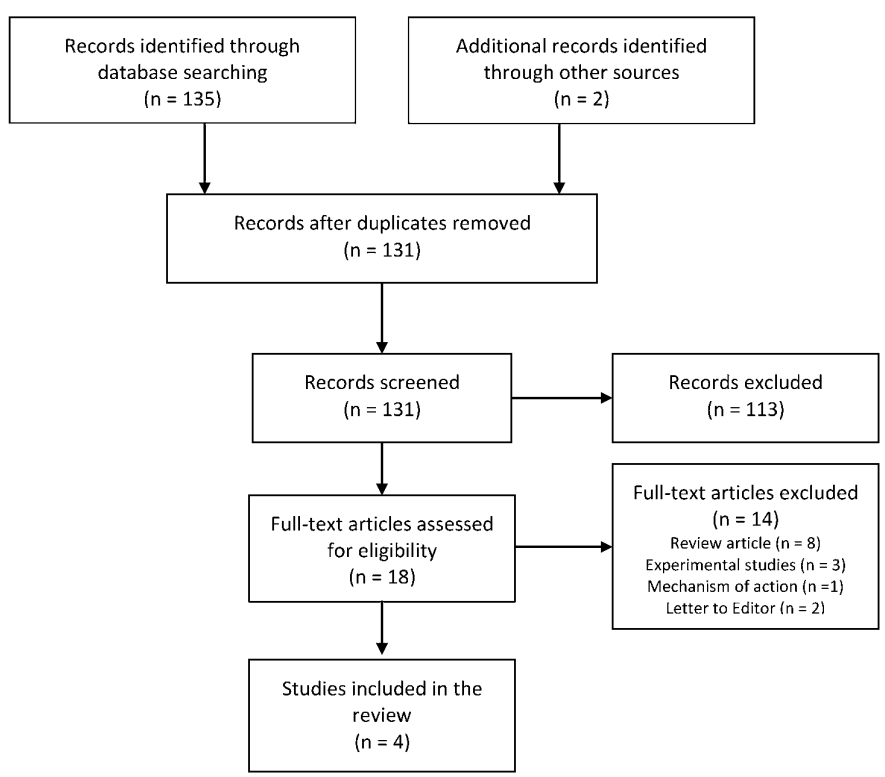

FIGURE 1: Flow chart of selected studies

The details of the clinical trials are summarized in Table 1. 


\section{Cureus}

\begin{tabular}{|c|c|c|c|c|c|c|c|}
\hline Reference & Design & Subjects & Intervention & Duration & $\begin{array}{l}\text { Type of } \\
\text { surgery }\end{array}$ & $\begin{array}{l}\text { Primary } \\
\text { end point }\end{array}$ & $\begin{array}{l}\text { Method of AF } \\
\text { identification }\end{array}$ \\
\hline $\begin{array}{l}\text { Miles et } \\
\text { al. }^{€} 2011 \\
{[14]}\end{array}$ & $\begin{array}{l}\text { Single-center, } \\
\text { non-randomized } \\
\text { retrospective } \\
\text { cohort study }\end{array}$ & 393 & $\begin{array}{l}\text { AO } 400 \mathrm{mg} / \text { day } 7 \text { days preoperatively and until } \\
\text { the } 10-14^{\text {th }} \text { postoperative day. RN } 1000 \mathrm{mg} \text { one } \\
\text { day before or on the day of surgery and } 1000 \mathrm{mg} \\
\text { twice daily until the } 10-14^{\text {th }} \text { postoperative day }\end{array}$ & 30 days & CABG & $\mathrm{AF}$ & $\begin{array}{l}\text { Continuous } \\
\text { electrocardiographic } \\
\text { monitoring }\end{array}$ \\
\hline $\begin{array}{l}\text { Tagarakis } \\
\text { et al. } 2013 \\
{[15]}\end{array}$ & $\begin{array}{l}\text { Prospective, } \\
\text { single-center, } \\
\text { single-blinded, } \\
\text { randomized study }\end{array}$ & 102 & $\begin{array}{l}\text { Randomized to receive either standard therapy } \\
\text { or RN } 375 \mathrm{mg} \text { twice daily } 3 \text { days prior to surgery } \\
\text { until day of discharge }\end{array}$ & 10 days & CABG & $\begin{array}{l}\mathrm{AF} \text { or other } \\
\text { arrhythmias }\end{array}$ & $\begin{array}{l}\text { Continuous } \\
\text { electrocardiographic } \\
\text { monitoring }\end{array}$ \\
\hline $\begin{array}{l}\text { Hammond } \\
\text { et al. }{ }^{*} \\
2015[16]\end{array}$ & $\begin{array}{l}\text { Single-center, } \\
\text { retrospective } \\
\text { cohort study }\end{array}$ & 205 & $\begin{array}{l}\text { RN group received RN } 1000 \mathrm{mg} \text { on the morning } \\
\text { of surgery and } 1000 \mathrm{mg} \text { twice daily until the } 7^{\text {th }} \\
\text { postoperative day. Non-RN group received } \\
\text { standard therapy }\end{array}$ & 7 days & $\begin{array}{l}\text { CABG, valve } \\
\text { and } \\
\text { combination } \\
\text { surgeries }\end{array}$ & $\mathrm{AF}$ & $\begin{array}{l}\text { Continuous } \\
\text { electrocardiographic } \\
\text { monitoring }\end{array}$ \\
\hline $\begin{array}{l}\text { Bekeith et } \\
\text { al. }{ }^{2} 2015 \\
{[17]}\end{array}$ & $\begin{array}{l}\text { Single-center, } \\
\text { double-blinded, } \\
\text { randomized trial }\end{array}$ & 54 & $\begin{array}{l}\text { Randomized to receive either placebo or RN } \\
1000 \text { mg twice daily } 48 \text { hours prior to surgery to } \\
\text { 14th postoperative day }\end{array}$ & 14 days & $\begin{array}{l}\text { CABG } \\
\text { and/or } \\
\text { aortic valve } \\
\text { replacement } \\
\text { surgeries }\end{array}$ & $\mathrm{AF}$ & Holter monitoring \\
\hline
\end{tabular}

\section{TABLE 1: Details of the studies included in the systematic review}

AO: amiodarone; AF: atrial fibrillation; $C A B G$ : coronary artery bypass grafting; RN: ranolazine.

$€$ : Surveillance was performed by continuous electrocardiography until the total length of stay.

¥: Surveillance was performed for at least seven days or until discharge by continuous electrocardiographic monitoring.

$£$ : Duration of treatment therapy was 14 days but surveillance was conducted for 30 days. Total of 51 patients completed this cohort study.

Baseline characteristics of the patients in the clinical trials are presented in Table 2. 


\begin{tabular}{|c|c|c|c|c|c|c|c|}
\hline & & $\begin{array}{l}\text { Age, } \\
\text { years }\end{array}$ & $\begin{array}{l}\text { Male } \\
\text { (\%) }\end{array}$ & $\begin{array}{l}\text { Hypertension } \\
\text { (\%) }\end{array}$ & $\begin{array}{l}\text { Diabetes } \\
\text { (\%) }\end{array}$ & $\begin{array}{l}\text { History of AF in } \\
\%\end{array}$ & LVEF (\%) \\
\hline \multirow{2}{*}{ Miles et al. 2011 [14] } & $\mathrm{RN}(\mathrm{n}=182)$ & $66.7 \pm 9.3$ & $127(70)$ & $158(87)$ & $71(39)$ & 4.5 & $57.7 \pm 9.8$ \\
\hline & $\begin{array}{l}\text { Control } \\
(n=211)\end{array}$ & $64.9 \pm 10.9$ & $162(77)$ & $182(86)$ & $76(36)$ & 7.6 & $54.7 \pm 12.7$ \\
\hline \multirow{2}{*}{ Tagarakis et al. 2013 [15] } & $\mathrm{RN}(\mathrm{n}=34)$ & $69 \pm 7$ & $24(71)$ & NR & NR & NR & $52.6 \pm 8.6$ \\
\hline & Control (n=68) & $67 \pm 8$ & $45(66)$ & NR & NR & NR & $53.8 \pm 9.4$ \\
\hline \multirow{2}{*}{$\begin{array}{l}\text { Hammond et al. } 2015 \\
\text { [16] }\end{array}$} & $\mathrm{RN}(\mathrm{n}=57)$ & $60.3 \pm 11.1$ & $38(67)$ & $45(79)$ & $20(35)$ & 1.8 & NR \\
\hline & Control (n=57) & $59.6 \pm 11.5$ & $38(67)$ & $48(84)$ & $20(35)$ & 1.8 & NR \\
\hline Bekeith et al. £ 2015 [17] & Control $(n=27)$ & $64.3 \pm 11.4$ & $44(81)$ & $48(89)$ & $22(41)$ & NR & $46.4 \pm 14.6$ \\
\hline IABLE 2: Baseline & aracteris & cs of pa & its & & & & \\
\hline AF: atrial fibrillation; CABG: cc & oronary artery bypa & ass grafting; $\mathrm{L}$ & EF: left ven & iricular ejection frac & on; NR: not re & ted; RN: ranolazine & \\
\hline Values are reported as mean $=$ & ISD or $n(\%)$. & & & & & & \\
\hline The data above is a repres & entation of both th & e RN and cont & rol group co & mbined. & & & \\
\hline
\end{tabular}

All studies were single-centered, one prospective [15], two retrospective [14,16] and included one randomized trial [17]. The total sample size was 754 ranging from 54 to 393 with the duration of follow up from seven to 30 days (median: 17 days; interquartile range (IQR): 18.25 ). The mean age was 65.4 years (IQR: 6.5) and was predominantly male (81\%). The mean LVEF was $53.04 \%$ (IQR: 6.5) and left atrial diameter 34.9 millimeters ( $\mathrm{mm}$ ) in the experiment as compared to $33.8 \mathrm{~mm}$ in the control group [15]. The comorbidities were indifferent between the two groups with hypertension being more prevalent at $86 \%$ and diabetes at $37 \%$. Two studies included patients with a history of $\mathrm{AF}[14,16]$ with a total of $10 \%$ in the control froup and $7 \%$ in the treatment group. The control group treatment varied among the studies. Standard therapy was used in two studies $[15,16]$ the results of which were not disclosed; in one study the comparison was against amiodarone [17] and the other was against placebo [17]. Ranolazine dosing, initiation, and termination varied among the studies as follows: (1) ranolazine $1000 \mathrm{mg}$ a day before surgery or on the day of surgery and then increased to $1000 \mathrm{mg}$ twice daily for 10 to 14 days [14]; (2) ranolazine $1000 \mathrm{mg}$ on the morning of the surgery and then twice daily for seven days [16]; (3) ranolazine $100 \mathrm{mg}$ twice daily 48 hours prior to surgery for 14 days [17]; (4) ranolazine $375 \mathrm{mg}$ twice daily, 72 hours prior to surgery, until the day of discharge for 10 days [15]. CABG was more common in the control group at 53\% (369/700) as compared to the treatment group of $37 \%$ (259/700), the valvular surgery in the treatment and control group was $3 \%$ versus $5 \%$, respectively [14-16]. Combined CABG and valvular surgery were indifferent in both groups [14-16].

On an average, the incidence of POAF was lower in the ranolazine group by $14 \%$ when compared to $32 \%$ in the non-ranolazine group. Hypotension was noted in the treatment group but resolved within 72 hours [16] with no other adverse effect noted and no difference in overall mortality and 30-day readmissions.

\section{Discussion}

POAF is typically a transient, reversible phenomenon that may develop in patients at risk. Multiple mechanisms are involved in the development of POAF including pericardial inflammation, catecholamine surge, autonomic imbalance, and interstitial mobilization of fluid with resultant changes in volume [5]. POAF is usually asymptomatic but is associated with increased morbidity and mortality [1]. Although perioperative beta-blockers, amiodarone, sotalol, calcium channel blockers, and magnesium have been used for the prevention of POAF, they are limited by adverse events (including hypotension and bradycardia) $[1,5]$ and by their suboptimal efficacy and potential for pro-arrhythmia risk [7].

Ranolazine, a piperazine derivative, exerts antiarrhythmic effects in both the ventricles and the atria and has been evaluated to prevent POAF. Although the exact mechanism for anti-arrhythmic effect is unknown, in the atrial tissue, ranolazine may suppress AF primarily by inhibiting peak sodium current (INa) and also causes inhibition of the delayed rectifier potassium (Ikr) current, leading to a decrease in atrial myocardium sensitivity and vulnerability to AF. Ranolazine reduces acetylcholine (Ach) mediated AF through different mechanisms by inhibiting INa, Ikr and, peak INa leading to a reduction of action potential upstroke and an increase in the diastolic threshold of excitation and post-repolarization refractoriness [18]. 
Several studies have demonstrated the clinical efficacy of ranolazine for the prevention of AF and was associated with a significant reduction of supraventricular tachyarrhythmia $(\mathrm{p}<0.001)$ as well as a $30 \%$ reduction in new-onset AF ( $\mathrm{p}=0.08$ ) in the Metabolic Efficiency with Ranolazine for Less Ischemia in NonST-elevation acute coronary syndromes - Thrombolysis in Myocardial Infarction (MERLIN-TIMI) 36 trial [10]. Murdock et al. demonstrated that ranolazine is helpful in maintaining sinus rhythm in patients with resistant AF [11]. Another study by the same authors suggested that a single dose of ranolazine $2000 \mathrm{mg}$ is effective in converting $77 \%$ of AF patients to sinus rhythm with no significant adverse drug reactions [12]. The Ranolazine in AF Following An ELectricaL CardiOversion (RAFFAELLO) study assessed the safety and efficacy of ranolazine in the prevention of AF recurrence after successful electrical cardioversion [19]. AF recurred in $56.4 \%, 56.9 \%, 41.7 \%$, and $39.7 \%$ of patients in the placebo, ranolazine $375 \mathrm{mg}$, ranolazine 500 $\mathrm{mg}$, and ranolazine $750 \mathrm{mg}$ groups, respectively [19]. The reduction in overall AF recurrence in the combined 500 -mg and 750-mg groups was of non-significance compared to the placebo group $(\mathrm{P}=0.053)$ and significant compared to 375-mg group $(\mathrm{P}=0.035)[15]$.

The results from this systematic review must be evaluated within the context of its potential limitations. Firstly, the included studies were single-sited, retrospective observational, and prospective evaluations of the report of POAF after ranolazine therapy. These studies included younger patients with a mean age of less than 70 years and mean left ventricular ejection fraction $>50 \%$ suggesting these patients were at low risk for developing POAF. Other important characteristics of left atrial size were not included. Many of the studies had small sample sizes with varied duration times and surveillance methods. Therapy in control group is diverse among all the studies and two studies [15-16] did not disclose the type of "standard therapy" being implemented. The dosing, initiation and termination of ranolazine also varied among the studies.

\section{Conclusions}

Although limited by lack of size and adequate control groups, the literature does suggest that ranolazine may be an efficacious and safe therapy for the prevention of POAF following cardiac surgery. However, multicenter, large, randomized controlled trials are warranted.

\section{Additional Information \\ Disclosures}

Conflicts of interest: In compliance with the ICMJE uniform disclosure form, all authors declare the following: Payment/services info: All authors have declared that no financial support was received from any organization for the submitted work. Financial relationships: All authors have declared that they have no financial relationships at present or within the previous three years with any organizations that might have an interest in the submitted work. Other relationships: All authors have declared that there are no other relationships or activities that could appear to have influenced the submitted work.

\section{References}

1. Kaireviciute D, Aidietis A, Lip GY: Atrial fibrillation following cardiac surgery: clinical features and preventative strategies. Eur Heart J. 2009, 30:410-425. 10.1093/eurheartj/ehn609

2. Andrews TC, Reimold SC, Berlin JA, Antman EM: Prevention of supraventricular arrhythmias after coronary artery bypass surgery. A meta-analysis of randomized control trials. Circulation. 1991, 84:III236-44.

3. Almassi GH, Schowalter T, Nicolosi AC, et al.: Atrial fibrillation after cardiac surgery: a major morbid event?. Ann Surg. 1997, 226:501-513.

4. Creswell LL, Schuessler RB, Rosenbloom M, Cox JL: Hazards of postoperative atrial arrhythmias . Ann Thorac Surg. 1993, 56:539-49.

5. Echahidi N, Pibarot P, O'Hara G, Mathieu P: Mechanisms, prevention, and treatment of atrial fibrillation after cardiac surgery. J Am Coll Cardiol. 2008, 51(8):793-801. 10.1016/j.jacc.2007.10.043

6. Fuster V, Rydén LE, Cannom DS, et al.: ACC/AHA/ESC 2006 guidelines for the management of patients with atrial fibrillation--executive summary: a report of the American College of Cardiology/American Heart Association Task Force on Practice Guidelines and the European Society of Cardiology Committee for Practice Guidelines (Writing Committee to Revise the 2001 Guidelines for the Management of Patients With Atrial Fibrillation). J Am Coll Cardiol. 2006, 48:854-906.

7. Fragakis N, Koskinas KC, Vassilikos V: Ranolazine as a promising treatment option for atrial fibrillation: electrophysiologic mechanisms, experimental evidence, and clinical implications. Pacing Clin Electrophysiol. 2014, 37:1412-20. 10.1111/pace.12486

8. Burashnikov A, Di Diego JM, Zygmunt AC, Belardinelli L, Antzelevitch C: Atrium-selective sodium channel block as a strategy for suppression of atrial fibrillation: differences in sodium channel inactivation between atria and ventricles and the role of ranolazine. Circulation. 2007, 116:1449-57.

9. Wu L, Shryock JC, Song Y, Antzelevitch C, Belardinelli L: Antiarrhythmic effects of ranolazine in a guinea pig in vitro model of long-QT syndrome. J Pharmacol Exp Ther. 2004, 310:599-605.

10. Scirica BM, Morrow DA, Hod H, et al.: Effect of ranolazine, an antianginal agent with novel electrophysiological properties, on the incidence of arrhythmias in patients with non ST-segment elevation acute coronary syndrome: results from the Metabolic Efficiency With Ranolazine for Less Ischemia in Non ST-Elevation Acute Coronary Syndrome Thrombolysis in Myocardial Infarction 36 (MERLIN-TIMI 36) randomized controlled trial. Circulation. 2007, 116:1647-52.

11. Murdock DK, Overton N, Kersten M, Kaliebe J, Devecchi F: The effect of ranolazine on maintaining sinus rhythm in patients with resistant atrial fibrillation. Indian Pacing Electrophysiol J. 2008, 8:175-81. 


\section{Cureus}

12. Murdock DK, Kersten M, Kaliebe J, Larrain G: The use of oral ranolazine to convert new or paroxysmal atrial fibrillation: a review of experience with implications for possible "pill in the pocket" approach to atrial fibrillation. Indian Pacing Electrophysiol J. 2009, 9:260-267.

13. Liberati A, Altman DG, Tetzlaff J, et al.: The PRISMA statement for reporting systematic reviews and metaanalyses of studies that evaluate healthcare interventions: explanation and elaboration. BMJ. 2009, 339:b2700. 10.1136/bmj.b2700

14. Miles RH, Passman R, Murdock DK: Comparison of effectiveness and safety of ranolazine versus amiodarone for preventing atrial fibrillation after coronary artery bypass grafting. Am J Cardiol. 2011, 108:673-6. 10.1016/j.amjcard.2011.04.017

15. Tagarakis GI, Aidonidis I, Daskalopoulou SS, et al.: Effect of ranolazine in preventing postoperative atrial fibrillation in patients undergoing coronary revascularization surgery. Curr Vasc Pharmacol. 2013, 11:98891.

16. Hammond DA, Smotherman C, Jankowski CA, et al.: Short-course of ranolazine prevents postoperative atrial fibrillation following coronary artery bypass grafting and valve surgeries. Clin Res Cardiol. 2015, 104:410-7. 10.1007/s00392-014-0796-x

17. Bekeith S, Meghani M, Shariff MA, et al.: Effect of ranolazine on the incidence of atrial fibrillation after cardiac surgery. Circulation. 2015, 132:13387.

18. Polytarchou K, Manolis AS: Ranolazine and its antiarrhythmic actions. Cardiovasc Hematol Agents Med Chem. 2015, 13:31-9.

19. De Ferrari GM, Maier LS, Mont L, et al.: Ranolazine in the treatment of atrial fibrillation: results of the dose-ranging RAFFAELLO (Ranolazine in Atrial Fibrillation Following An ELectricaL CardiOversion) study. Heart Rhythm. 2015, 12:872-8. 10.1016/j.hrthm.2015.01.021 